American Journal of Pharmaceutical Education 2020; 84 (2) Article 7172.

\title{
BRIEF
}

\section{A Pilot Study Regarding Pharmacy Law Education Across Doctor of Pharmacy Programs}

\author{
Ettie Rosenberg, PharmD, JD, ${ }^{a}$ Erin L. Albert, MBA, PharmD, JD, ${ }^{\mathrm{b}}$ Geoffrey A. Mospan, PharmD, \\ Shannon Panther, PharmD, ${ }^{\mathrm{d}}$ James Ruble, PharmD, JD, ${ }^{\mathrm{e}}$ Robert L. Stein, PharmD, JD ${ }^{\mathrm{f}}$ \\ ${ }^{a}$ West Coast University School of Pharmacy, Los Angeles, California \\ ${ }^{\mathrm{b}}$ Pharmacy Podcast Network, Pharmacy Times, Indianapolis, Indiana \\ ${ }^{c}$ Wingate University School of Pharmacy, Wingate, North Carolina \\ ${ }^{\mathrm{d}}$ Washington State University College of Pharmacy, Spokane, Washington \\ ${ }^{\mathrm{e}}$ University of Utah, College of Pharmacy, Salt Lake City, Utah \\ ${ }^{\mathrm{f}}$ Keck Graduate Institute, School of Pharmacy, Claremont, California \\ Submitted May 14, 2018; accepted August 6, 2019; published February 2020.
}

Objective. To describe the features of pharmacy law education in Doctor of Pharmacy (PharmD) programs in the United States.

Methods. A review of the literature found no prior published data describing the delivery of pharmacy law education across PharmD programs in the United States. Members of the Pharmacy Law Educators Subcommittee of the American Society for Pharmacy Law (ASPL) developed questions for a survey. The survey was administered electronically to all 139 American Association of Colleges of Pharmacy (AACP) member institutions in the summer of 2016. A link to complete the 32-item online survey was distributed via email to the pharmacy law educator or associate dean at each AACP member institution. Results. Of the 139 PharmD programs surveyed, 49 completed the survey instrument, yielding a response rate of $35.2 \%$. Variations between programs were found in the professional background of pharmacy law instructors and assessment strategies for pharmacy law courses, as well as in the structure and placement of the main pharmacy law course within the various curricula.

Conclusion. This pilot study represents the first and only known attempt to examine delivery of pharmacy law education across colleges of pharmacy. The variations between programs found in this study highlight the need for further investigation into this area of pharmacy education.

Keywords: pharmacy law, curriculum, legal, education

\section{INTRODUCTION}

Accreditation standards require Doctor of Pharmacy (PharmD) degree programs to include content on pharmacy law and regulatory affairs "at an appropriate breadth and depth" and explicitly recognize such content to be "central to a contemporary, high-quality pharmacy education." Specifically, the Accreditation Council for Pharmacy Education (ACPE) Standards 2016 provides that PharmD curricula must incorporate critical law content including "federal and appropriate state-specific statutes, regulations, policies, executive orders, and court decisions that regulate the practice of pharmacy, including the mitigation of prescription drug abuse and diversion."

Corresponding Author: Ettie Rosenberg, West Coast University School of Pharmacy, 590 N. Vermont Ave., Los Angeles, CA 90004. Tel: 323-454-5024. Email:

erosenberg@westcoastuniversity.edu
Presumably, competency in those content areas lays the foundation for pharmacy graduates to be armed with a working knowledge of the legislative and regulatory boundaries within which pharmacists practice, and the ability to advocate for its expanding scope in the evolving healthcare landscape. However, Standards 2016 provides only a broad overview for the requisite pharmacy law content.

Ideally, there would be published studies to support the recommendations made by ACPE. Instead, there is a remarkable deficiency of literature specifically addressing pharmacy law education, with no published literature related to pedagogic methods for delivery, sequencing, or overall scope of didactic pharmacy law curricula in PharmD programs. Pharmacy law education has been seemingly overlooked in the literature. Thus, the American Society for Pharmacy Law (ASPL) Pharmacy Law Educators Subcommittee sought to highlight that pharmacy law content is an essential component of a PharmD 


\section{American Journal of Pharmaceutical Education 2020; 84 (2) Article 7172.}

curriculum. Further, the subcommittee recognized that scholarly attention to current pedagogic practices in pharmacy law curricula is warranted. At the federal level, statutes authorizing federal agencies to publish regulations and enforcement provisions directly impact pharmacists and pharmacies, as well as the gamut of players in the pharmaceutical industry and supply chain. Yet other federal statutes exact similar impact, albeit indirectly, through regulation of the drug products handled daily by pharmacists and pharmacies. Moreover, each state has independent jurisdiction over its own pharmacy practice act, regulating the licensing of pharmacists and pharmacies and its own controlled substance statutes. Thus, integrating pharmacy law content into PharmD curricula through robust and evidence-based pedagogic delivery methods should ensure that pharmacy graduates possess a solid foundational understanding of the pervasive federal and state regulatory frameworks impacting pharmacy practice and their application to the profession, and accordingly, that pharmacy graduates are indeed "practice ready."

Accordingly, the Pharmacy Law Educators Subcommittee focused on the observed need to identify strategies and methods for delivery and ultimately assessment of pharmacy law education. The subcommittee's objective was to acquire information through the scholarly collection and evaluation of data on pharmacy law education in the United States. The seminal nature of the subcommittee's exploration guided a probative effort to disseminate a survey with inquiries about demographics of pharmacy law faculty members (who); sequencing of pharmacy law content (when); and teaching-learning strategies (how) for delivery of primary pharmacy law content. The subcommittee reasoned that conducting a pilot study that examined delivery of pharmacy law education, collected and reported demographic information obtained from schools and colleges of pharmacy, the subcommittee could reasonably advise the Academy regarding current practices in pharmacy law education. Likewise, the analysis of data from future studies would afford a longitudinal mechanism by which to identify, develop and recommend evidencebased best practices for delivery of pharmacy law education, while also promoting an exchange of ideas across PharmD programs. As the first step of this initiative, the survey was pilot tested in the summer of 2016. The objective of the pilot survey was to gather preliminary insight about delivery of pharmacy law education in the United States to inform a further and more robust investigation.

\section{METHODS}

This was a cross-sectional survey which studied the delivery of pharmacy law education in the United States. An online survey approach was used to collect information on current practices in pharmacy law education. The study was deemed exempt by the Washington State University Institutional Review Board (IRB) Office of Research Assurances.

Members of the ASPL Pharmacy Law Educators Subcommittee identified and developed the framework of inquiry and the survey questions on pharmacy law pedagogy. The survey tool contained 32 questions on delivery of pharmacy law education, including: faculty demographics (who delivers the pharmacy law content); scope (what pharmacy law content is delivered); sequencing (when primary pharmacy law content is delivered); and teaching-learning strategies (how primary pharmacy law content is delivered). A list of the 32 items comprising the pilot survey is presented in Appendix 1.

The SurveyMonkey platform (SurveyMonkey Inc., San Mateo, CA) was used for data collection. The survey was conducted during the narrow period between June 22, 2016 and July 31, 2016. ACPE Standards 2016 became effective July 1,2016. At the start of the data collection period, an email was sent to the pharmacy law educator or associate dean at each PharmD program that explained the survey's purpose, provided a link to the survey, and specified a deadline of July 31, 2016, for the survey's target completion. A reminder e-mail was sent to nonresponders on July 8, 2016, and the survey link was inactivated on August 8, 2016. Descriptive data analyses (i.e., frequency and percentage) were performed to identify the characteristics associated with the current delivery of pharmacy law education in the United States.

\section{RESULTS}

Of the 139 AACP member institutions in 2016, 49 responded to the pilot survey, yielding a response rate of $35.2 \%{ }^{2}$ The demographics of the responding schools and colleges of pharmacy can be found in Table 1. The majority $(n=27,55 \%)$ of schools that responded were public institutions. Most of the responding schools $(n=28,57 \%)$ had an average class size of 51-100 students.

The professional and employment characteristics of pharmacy law educators at the responding schools are listed in Table 2. Nearly all of the pharmacy law educators were pharmacists, attorneys, or both. The academic and professional backgrounds of the pharmacy law professors varied significantly, with pharmacists being the most common $(n=25)$, followed by pharmacist-attorneys $(n=23)$, non-pharmacist attorneys $(n=6), P h D$ pharmaceutical scientists $(n=4)$, and one professor with a doctorate in social and administrative sciences. Most $(n=37$, $76 \%$ ) of the programs that responded employed a fulltime pharmacy law faculty member $(n=37,76 \%)$. Only five programs reported using a teaching assistant or graduate student in the pharmacy law course. 


\section{American Journal of Pharmaceutical Education 2020; 84 (2) Article 7172.}

Table 1. Demographic Data for US Doctor of Pharmacy Programs Responding to a Survey on Pharmacy Law Education $(\mathrm{N}=49)$

\begin{tabular}{lr}
\hline Participants & No. (\%) \\
\hline Institution Type & \\
$\quad$ Public & $27(55)$ \\
Private & $22(45)$ \\
Location & \\
$\quad$ Northeast & $11(22)$ \\
Midwest & $8(16)$ \\
South & $15(31)$ \\
West & $14(29)$ \\
US Territory & $1(2)$ \\
Approximate Class Size & \\
$<50$ & $2(4)$ \\
$51-100$ & $28(57)$ \\
$101-150$ & $12(25)$ \\
$151-200$ & $6(12)$ \\
$>200$ & $1(2)$ \\
\hline
\end{tabular}

Data describing the delivery of pharmacy law content is reported in Table 3 , with programs indicating that a majority of pharmacy law content was taught in one semester $(n=43,88 \%)$ and within a standalone course $(n=45,92 \%)$. Most $(n=34,69 \%)$ institutions maintained only a single primary pharmacy law course that incorporated all pharmacy law content delivered within the PharmD curriculum. The number of credit hours, the number of educators teaching the primary pharmacy law course, and its professional year (P1, P2, or P3) placement (varied widely (Table 3$)$. While two $(\mathrm{n}=23,47 \%)$ or three

Table 2. Characteristics of Pharmacy Law Educators in US Doctor of Pharmacy Programs $(\mathrm{N}=49)$

\begin{tabular}{lc}
\hline Characteristic & No. (\%) \\
\hline Professional background $^{\text {a }}$ & \\
Pharmacist (non-attorney) & 25 \\
Attorney (non-pharmacist) & 6 \\
Pharmacist Attorney & 23 \\
PhD/pharmaceutical sciences & 4 \\
PhD/social and administrative sciences & 1 \\
Employment status of main educator & $11(22)$ \\
Adjunct & $37(76)$ \\
Full-time employment from college/school & 0 \\
Part-time employment from college/school & $1(2)$ \\
No Response & \\
Practice setting of adjunct or part-time faculty & 4 \\
Law firm & 4 \\
Pharmacy & 1 \\
Board of pharmacy & 2 \\
No response
\end{tabular}

${ }^{a}$ Multiple answers were accepted for institutions with more than one pharmacy law educator
Table 3. Details of Pharmacy Law Content Delivery Within the Curriculum of US Doctor of Pharmacy Programs $(\mathrm{N}=49)$

\begin{tabular}{lc}
\hline Characteristic & No. (\%) \\
\hline Format of pharmacy law course $^{\mathrm{a}}$ & \\
Stand-alone course & 45 \\
Integrated instruction in a required course & 4 \\
Integrate instruction throughout several & 11 \\
$\quad$ courses & \\
Two courses & 2 \\
Miscellaneous lectures in other courses & 3 \\
No response & 1 \\
Year pharmacy law is taught in the curriculum & \\
First professional year & \\
Second professional year & 24 \\
Third professional year & 16 \\
Duration of pharmacy law course & 31 \\
One semester & \\
Two semesters & $43(88)$ \\
Other & \\
Number of credit hours & $4(8)$ \\
1 & $2(4)$ \\
2 & $1(2)$ \\
3 & $23(47)$ \\
4 & $20(41)$ \\
Other & $3(6)$ \\
\end{tabular}

Number of educators in the pharmacy law course

$1 \quad 33(67)$

$2 \quad 10(21)$

$3 \quad 6(12)$

Setting of pharmacy law lectures
One section $^{\mathrm{d}}$
$46(94)$

Multiple sections

Number of courses in curriculum with 3 or more pharmacy law lectures

1

2

$33(67)$

$15(231)$

$1(2)$

${ }^{a}$ Multiple answers accepted for this item

${ }^{\mathrm{b}}$ Other responses included 10 weeks and two quarters

c 2.5 hours and five quarter-credits

${ }^{\mathrm{d}}$ Two respondents reported that students received additional instruction in recitation/break-out sections

$(n=20,41 \%)$ courses were among the most common models by which the primary pharmacy law content was delivered, its placement within the PharmD curriculum varied: P1 $(n=24), P 2(n=16)$, and P3 $(n=31)$.

Table 4 presents the data on assessment methods used in pharmacy law courses, which encompassed traditional summative assessments and formative assessments involving active-learning techniques. Of the traditional summative assessment methods, almost all $(\mathrm{n}=44,90 \%)$ programs used multiple-choice examinations, which are comparable to the Multistate Pharmacy 


\section{American Journal of Pharmaceutical Education 2020; 84 (2) Article 7172.}

Table 4. Assessment Methods Used in Pharmacy Law Courses Within the Curriculum of US Doctor of Pharmacy Programs $(\mathrm{N}=49)$

\begin{tabular}{lc}
\hline Assessment Type $^{\text {a }}$ & $\begin{array}{c}\text { Responding } \\
\text { Institutions, No. }\end{array}$ \\
\hline Multiple choice examinations & 44 \\
Essays & 9 \\
Oral presentations & 8 \\
Short answer questions & 14 \\
Mock trials or mock board $\quad 5$ \\
$\quad$ of pharmacy meetings & \\
Team or group projects & 15 \\
Other & 13 \\
No response & 4 \\
\hline
\end{tabular}

Jurisprudence Examination (MPJE) or state-specific jurisprudence licensing examinations; 29\% $(n=14)$ used short-answer questions; and $18 \%(n=9)$ used essays as an assessment tool. With respect to formative assessments using active learning, 31\% $(\mathrm{n}=15)$ of responding programs reported using team or group projects, and 10\% $(n=5)$ reported mock trials or mock board of pharmacy meetings to assess student learning (ie, students roleplayed parties in mock trials, board meetings, or administrative hearings). All 18 programs used more than one of these assessment methods. Various other assessments that the programs reported using included weekly quizzes, clicker quizzes/class participation, attendance at a board of pharmacy meeting, and self-directed learning modules.

A substantial majority of the responding programs $(\mathrm{n}=39,89 \%)$ identified the MPJE as the pharmacy law licensing examination in their respective states, and specified their respective pharmacy law curricula were deliberately designed to prepare students for the MPJE. Five programs (11\%) acknowledged a state-specific or territory-specific examination requirement, and similarly reported that their program's primary law course targeted the respective state/territorial licensing board examination rather than focusing on the MPJE.

\section{DISCUSSION}

The ACPE Standards 2016 focus on concepts "central to a contemporary, high quality pharmacy education" and "essential for pharmacists to master" with a stated goal "to ensure that critical areas of learning are included in the curricula of all programs." ACPE Standards do not dictate how lessons are structured or how content is delivered. ${ }^{1}$ In other words, while all PharmD programs must satisfy the broadly framed accreditation standards for pharmacy education, individual programs retain the latitude to determine when and how pharmacy law content is delivered and which additional topics are covered. Consistent with the latitude afforded by ACPE, this pilot study data noted variations in delivery (how), sequencing of pharmacy law courses (when), and pharmacy law topics and course offerings (what) across the 49 programs that responded. Differences in the delivery, sequencing, and scope of pharmacy law content in a PharmD program may serve to distinguish one PharmD program from others in the academy and can be a deliberate or desirable result. Given that this was a pilot survey, the rationale for placement or sequencing of the pharmacy law content within a curriculum was not explored with this foray, though admittedly that could be a line of inquiry in a future survey.

We identified a historic paucity of literature on pharmacy law education, which is what motivated us to conduct the survey. The pilot survey attracted responses from only 49 programs, which means the data collected represents only $35 \%$ of AACP member institutions in $2016(\mathrm{~N}=139) .{ }^{2}$ Accordingly, these results may not be generalizable to the remaining non-reporting programs because of statistical limitations imposed by the relatively low response rate.

Nonetheless, these data provide a relevant starting point for future studies. Indeed, the results of this pilot initiative underscore the necessity for further investigation and a longitudinal study to bridge the considerable information gap concerning delivery of pharmacy law education. Anecdotally, we do not believe that delivery of pharmacy law education has changed significantly since the 2016 pilot survey. Moreover, ACPE Standards 2016 became effective on July 1, 2016, precisely in the middle of the data collection period (June 22, 2016, to July 31, 2016) for the pilot survey. ${ }^{1}$ Therefore, in the absence of any prior literature, the data from this pilot survey provide an invaluable baseline examination and offer relevant and instructive insight about trends in the delivery of pharmacy law education. ${ }^{1}$

\section{CONCLUSION}

Results of this pilot study illustrate wide variations in delivery of pharmacy law curricula as reported by the responding PharmD programs. Variations encompass how primary pharmacy law content is delivered (teaching-learning strategies); when primary pharmacy law content is delivered (sequencing); and what pharmacy law topics and course offerings are delivered (content) across the 49 programs that responded. Because of the current limited data set and the importance of pharmacy law education to a pharmacy career, there is clearly need for further investigation in this area. Armed with the lessons learned from these pilot study results, we have 


\section{American Journal of Pharmaceutical Education 2020; 84 (2) Article 7172.}

planned a revised and improved survey of pharmacy law education which will include additional items inquiring about delivery of pharmacy ethics content in PharmD curricula.

\section{ACKNOWLEDGMENTS}

The authors thank the 2016-2017 ASPL Board at Large for supporting this research project, as well as members of the ASPL Pharmacy Law Educators Subcommittee for their assistance in developing and administering the pilot survey. Additionally, the authors thank Shih-Ying (Audrey) Hsu, PhD, and Sarah
McBane, PharmD, for their expert assistance with this manuscript.

\section{REFERENCES}

1. Accreditation Council for Pharmacy Education. Accreditation Standards and Key Elements for the Professional Program in Pharmacy Leading to the Doctor of Pharmacy Degree ("Standards 2016"). Published February 2015. https://www.acpe-accredit. org/pdf/Standards2016FINAL.pdf. Accessed February 22, 2020

2. American Association of Colleges of Pharmacy. Academic Pharmacy's Vital Statistics. https://www.aacp.org/article/academicpharmacys-vital-statistics. Accessed February 22, 2020. 


\section{American Journal of Pharmaceutical Education 2020; 84 (2) Article 7172.}

Appendix 1. 2016 ASPL Pilot Survey: Delivery of Pharmacy Law Education (Item options appear in parentheses)

\section{Survey Items}

Who teaches pharmacy law at your school/college? (Yes/No; See \#5: Open-Ended Response)

Identify the school/college of pharmacy described. (If you prefer not to name a school, please enter a geographic location, such as Midwest, West, South, Northwest, New England, etc.) (Open-Ended Response)

Is the school/college of pharmacy you describe public or private? (Select: public, private, or other-specify)

What is the approximate class size per class at your school/college of pharmacy? (Select: 51-100; 101-150; 151-200; >200; Other-specify)

Who teaches pharmacy law at your school of pharmacy? (If you have a primary coordinator for pharmacy law at your school and/ or multiple educators in pharmacy law, please list the coordinator first.) (Name(s): Open-Ended Response)

What is the professional background of the faculty teaching pharmacy law at your school or college? (Check all that apply: pharmacist; attorney; pharmacist-attorney; $\mathrm{PhD} /$ pharmaceutical scientist; other-specify)

How many courses in your school of pharmacy have law as a core* part of the respective course? $\left({ }^{*}\right.$ Core $=$ greater than 3 or more law lectures in the course) (Select: 1,2,3,> 3 law lectures in the course)

How is the pharmacy law curriculum taught? (Check all that apply: stand-alone course; integrated instruction in a required course; integrated throughout several courses in several professional years; other-specify)

In which professional year(s) is/are the pharmacy law coursework taught? (Check all that apply: P1; P2; P3; P4; other-specify)

How many semester(s) is the main pharmacy law course? (Select: 1 semester; other-specify)

In which semester(s) of the academic year is the pharmacy law course taught? (Check all that apply: fall; spring; summer; otherspecify)

How many credit hours is your program's pharmacy law course? (Select: $1 ; 2 ; 3$; other-specify)

If your school/college has a main pharmacy law course, how many professors/instructors teach in that course? (Select: 1; 2; 3; other-specify)

Are any teaching assistants (TAs) involved in the course? If so, please state their current position (eg, graduate student, fellow, hospital resident, community pharmacist, lawyer, law student, etc.)

Do you teach pharmacy law in multiple sections or break your class/cohort into smaller sections? (Select: all in one section; divide cohort into smaller sections; other-specify)

Is the main pharmacy law professor/course coordinator: (Select One: FT; PT; adjunct; other-specify)

What type of setting does the main pharmacy law professor/instructor/coordinator practice in (assuming employed part-time and/ or as an adjunct by school/college of pharmacy)? (Select: pharmacy; law firm/ practice; consulting; other-specify)

What type(s) of legal issue(s) are discussed in your pharmacy law course, beyond state pharmacy laws, the FDCA, CSA, HIPAA, and other state/federal pharmacy laws? (Check all that apply: USP 800; DQSA; Compounding USP 795,797; business legal issues; employment law issues; insurance/billing; clinical research; provider status; public health; medical cannabis; death with dignity; capital punishment; investigational drugs/right to try; fraud/waste/abuse; immunization refusal/ mandatory immunizations; other-specify)

Does your pharmacy law course also address policy? If so, describe how (Open-Ended Response)

Does your pharmacy law course address regulatory affairs? Yes/No (Drug development, working with FDA, other agencies, etc.) If yes, how many hour(s) of lecture are dedicated to it in the pharmacy law course? (Open-Ended Response)

Where do you obtain reference materials for your pharmacy law instruction? Select and list from Textbooks List (both state and federal): reference books: list; major online resources: list; State General Assembly or Board of Pharmacy: list; visual learning tools: list; other-specify: list)

How do you assess student learning in pharmacy law? (Check all that apply: multiple choice examinations - like MPJE or CPJE; essays; oral presentations; short answer questions; mock trials or mock board of pharmacy meetings; team or group projects; other-specify)

If you have student presentations in pharmacy law, are these resented individually or in teams? (Check all that apply: individually; teams; other-specify)

How many hours do you need to prepare for one hour of pharmacy law lecture? (Select: $1 ; 2 ; 3 ; 4 ; 5 ;>5$ )

Does your school/college of pharmacy offer any pharmacy law electives? If so, list: (Open-Ended Response)

Have you/your school started any innovative assignment, approach, or method to teach pharmacy law?

If so, describe briefly: (Open-Ended Response)

Does your school of pharmacy offer a MPJE or pharmacy law review course for graduates? If so, please provide information if you have it: (Open-Ended Response)

Does your university also have a law school? Yes/No

If so, how have you or have you partnered with them relative to pharmacy law? (Open-Ended Response) 


\section{American Journal of Pharmaceutical Education 2020; 84 (2) Article 7172.}

Appendix 1. (Continued)

Survey Items

If you answered yes to the previous question, approximately how many students pursue a joint PharmD/JD at your school if a joint degree is offered (respond per year)? (Open-Ended Response)

Does your state/jurisdiction require a certain number of pharmacy law continuing education credit hours per year or per licensure/CE cycle for pharmacists? If so, how many hours? Describe: (Open-Ended Response)

Does your state/jurisdiction use MPJE? If not, what exam, if any, covers pharmacy law? (Check all that apply: (yes; no; otherspecify)

If you have changed your curriculum in pharmacy law to prepare for the "new" MPJE* describe those changes? (*assuming your jurisdiction utilizes MPJE): (Open-Ended Response) 